\title{
Role of Patch Testing in Chronic Spontaneous Urticaria
}

Jonathan Bar'

Sari Godlewicz ${ }^{2}$

Arieh Ingber $\mathbb{D}^{2}$

Eli Sprecher $\mathbb{D}^{1,3}$

Dan Slodownik (D) ${ }^{1,3}$

'Department of Dermatology, Tel Aviv Sourasky Medical Center, Tel Aviv, Israel; ${ }^{2}$ Department of Dermatology, HadassahHebrew University Medical Center, Jerusalem, Israel; ${ }^{3}$ Sackler School of Medicine, Tel - Aviv University, Tel-Aviv, Israel
Correspondence: Dan Slodownik

Tel Aviv Sourasky Medical Center,

6 Weizmann Street,

Tel Aviv, 6423906, Israel

Tel +972 3-6973585

Fax +972 3-6974998

Email dans@tlvmc.gov.il
Background: Chronic spontaneous urticaria (CSU) is a common debilitating condition. Although not completely understood, the main pathomechanism involves autoimmune-related mast-cell degranulation. Patch test (PT) is the gold standard for the diagnosis of type IV cutaneous hypersensitivity. The relevance of PT to the diagnosis of CSU is debatable.

Objective: We aimed at determining the role of PT in selected patients with CSU.

Methods: In this retrospective study, we reviewed cases of patients referred for patch testing at our clinic. We compared results of patients with CSU $(n=134)$ and patients with suspected allergic contact dermatitis ( $n=680$; control group).

Results: Among patients in the CSU group, 3\% of patients had relevant reactions to PT, indicating that contact allergen avoidance resulted in resolution of all skin findings. Metals and textile dyes were the most relevant allergens. No significant differences were found between the groups with regard to the percentage of patients with positive PT and hapten reaction profiles. Patients from the CSU group were significantly older (4.1 years on average, $P<0.05$ ), consisted of more females, and were less likely to have atopic trait ( $46 \%$ vs $58 \%, \mathrm{P}<0.05)$.

Conclusion: In some of patients, PT may assist in determining the cause of CSU.

Keywords: chronic spontaneous urticaria, patch test, contact dermatitis

\section{Background}

Urticaria is one of the most common skin conditions and manifests as pruritic wheals. ${ }^{1,2}$ Although most cases have an unknown trigger, some can be triggered by factors such as food, medications, mechanical stimuli, latex, temperature, UV radiation, or water. When urticaria persists for more than 6 weeks, it is considered "chronic." Moreover, if no cause can be defined, it is considered "idiopathic." Chronic spontaneous urticaria (CSU, also known as chronic idiopathic urticaria) is responsible for $66-93 \%$ of chronic urticaria cases. ${ }^{3}$ CSU may severely impair the quality of life of patients and negatively influence health economy burden. ${ }^{4}$

The pathomechanism of CSU is mainly related to mast cell inappropriate degranulation, ${ }^{1}$ which can be triggered by immune or nonimmune responses. Immunologic responses, including IgE antibodies ("allergic response"), immune complexes, and autoimmune antibodies, interact with mast cell receptors. ${ }^{5}$ The mast cells, in turn, release granules containing histamine, leukotrienes, and other effectors, which contribute to the formation of wheals and associated pruritus.

In contrast to $\mathrm{CSU}$, the pathomechanism of allergic contact dermatitis (ACD) is mainly related to antigen presenting cells (APCs)-induced T cell responses. ${ }^{6}$ Other than a different mechanism, the clinical presentation is also different - manifesting mostly as an erythematous plaque with well-defined margins corresponding to the area 
of contact, sometimes with scales, crust or vesicles. The use of the patch test (PT) is considered the gold standard for the diagnosis of delayed-type, cell-mediated reactions to exogenous materials ${ }^{7}$ and may also be used in the evaluation of drug reactions, ${ }^{8,9}$ both immediate and delayed.

In recent years, these mechanisms have been shown to be intertwined, with mast cells and IgE being associated with the pathogenesis of $\mathrm{CD},{ }^{6,10}$ and APCs and CD4 T-helper cells being involved in the development of CSU. ${ }^{5}$

Early studies were conducted to establish the possible role of PT in chronic urticaria evaluation. ${ }^{11,12}$ Later, Guerra et al also debated the role of contact sensitization in chronic urticaria theorizing that it plays a role in triggering urticaria. ${ }^{13}$ They demonstrated that $41 \%$ of patients with CSU tested positive for contact allergens, and contact avoidance led to full recovery. Similar studies with contradictory results have been reported. ${ }^{14-16}$ Moreover, some studies applied the PT technique but with common aeroand food-allergens instead of the common contact allergens. For example, it has been postulated that house dust mite allergens penetrate the stratum corneum and activate Langerhans and mast cells. ${ }^{17,18}$

To further investigate the role of contact allergens in CSU, we compare here the yield of PT in a group of CSU patients and in a large control group consisting of patients referred for evaluation of suspected allergic contact dermatitis.

\section{Methods}

\section{Study Design and Patients}

We performed a retrospective case-control study of all patients referred for patch testing between 2010 and June 2021. Epidemiological and demographic data were retrieved, including age, sex, atopy status (history of atopic dermatitis, allergic rhinitis, and asthma) other past medical history, current medications, occupation, and rash pattern.

Patients who were using corticosteroids (either systemic for 30 days or topical for 14 days), or those with a recent tan or phototherapy treatment, were excluded.

\section{Patch Test}

All patients were administered the European baseline and case relevant series (Chemotechnique Diagnostics, Vellinge, Sweden). The allergens were placed in Finn Chambers on Scanpor ${ }^{\circledR}$ tape $(20 \mathrm{mg}$ in $8-\mathrm{mm}$ chambers $)$ and immediately applied to the patient's upper back.
Allergens were left in place for 2 days, and readings were obtained on day 4 for all patients. The patients were instructed to return on day 7 if additional reactions were observed later. Positive reactions were scored as weak $(+)$, strong $(++)$, and extreme $(+++)$ according to the International Contact Dermatitis Research Group and European Society of Contact Dermatitis (ESCD) criteria. $^{7}$ Clinical relevance was defined according to the ESCD criteria. Complete remission of the symptoms after 3 months of strict avoidance of the culprit allergen supported clinical relevancy. Only "weak positive" $(+)$ reactions and above were considered positive for the analysis.

\section{Statistical Analyses}

Patients were divided into two groups: those who were referred for suspected allergic contact dermatitis, and those who were referred for CSU. Statistical analyses were performed to compare the two groups.

Categorical variables were compared using the $\chi^{2}$ test and Fisher exact test. Continuous variables were compared using Student $t$-test and the Mann-Whitney $U$-test. All statistical tests were two-sided. A p-value $<0.05$ was considered statistically significant and was corrected using the Bonferroni correction for multiple comparisons when required. SPSS was used for all statistical analyses (IBM SPSS Statistics, ver. 26, IBM Corporation, Armonk, NY, USA).

The study was conducted in compliance with national, international ethical guidelines established by Helsinki Declaration of the World Medical Association. It was approved by the ethics review committee of HadassahHebrew University Medical Center, Jerusalem, Israel. Informed consent was waived due to the retrospective nature of the study. Patients' data confidentiality was strictly protected.

\section{Results}

Patch tests were performed on 134 patients with CSU and 680 patients with suspected allergic contact dermatitis. Aggregated demographic data are presented in Table 1. Patients from the CSU group were significantly older (4.1 years on average, $P<0.05)$ and consisted of more females (77\% vs $59 \%, P<0.01)$. Atopy status was also tested; atopic patients were considered as such if they or first-degree family relatives had a history of allergic rhinitis, atopic dermatitis, or asthma. CD patients had statistically significant more atopic diseases ( $58 \%$ vs $46 \%, \mathrm{P}<0.05$ ), On the other hand, there was no statistically significant difference in occupational profiles. 
Table I Patient Demographics and Clinical Characteristics

\begin{tabular}{|l|l|l|l|}
\hline & CD Group (n = 680) & CSU Group (n = 134) & p-value \\
\hline Age [years] (mean) & 43.9 & 48 & $\mathrm{p}<0.05$ \\
Gender [male] (\%) & $41 \%$ & $23 \%$ & $\mathrm{p}<0.01$ \\
Atopic background [n] (\%) & $391(58 \%)$ & $60\left(\right.$ of $\left.13 I^{\dagger}, 46 \%\right)$ & $\mathrm{p}<0.05$ \\
Patients with positive reactions [n] (\%) & $251(37 \%)$ & $46(34 \%)$ & $\mathrm{p}>0.05$ \\
Patients with relevant positive reactions [n] (\%) & $150(22 \%)$ & $4(3 \%)$ & $\mathrm{p}<0.01$ \\
\hline
\end{tabular}

Notes: ${ }^{\dagger}$ Three patients had an unknown atopy status; $\mathrm{p}$-value $<0.05$ was considered statistically significant.

Abbreviations: CD, Contract Dermatitis; CSU, Chronic spontaneous urticaria; $n$, number.

Regarding positive PT results, there was no statistically significant difference between the two groups in the rate of positive reactions or the number of reactions per patient.

Thirty-six percent of the referred patients had a positive PT. The 10 topmost allergens that caused contact dermatitis are presented in Table 2 .

Regarding relevant reactions, the proportion of the patients in the CSU group with relevant reactions was significantly lower than that of the patients in the $\mathrm{CD}$ group. Four of the CSU patients (3\%) had a relevant reaction to a contact allergen, meaning their CSU had resolved within three months of contact avoidance with the offending allergen: One patient was allergic to chloramphenicol, one patient was allergic to nickel, and two patients had relevant reactions to three contact allergens each (Disperse blue 106, Disperse blue 124, and Disperse blue mix 106/124; and potassium dichromate, nickel, and cobalt, respectively).

There was no statistically significant difference between the CSU and CD groups, on comparing relevantonly reactions, or any reaction regardless of relevancy
(pAdj < 0. 00023526 using Bonferroni correction for multiple comparisons).

\section{Discussion}

CSU, though often classified as an IgE-dependent reaction, features a more complex pathomechanism. ${ }^{1,5}$ Cellular immunity seems to play a role in the pathogenesis of CSU. ${ }^{5}$

Boonk and van Ketel $^{11}$ demonstrated positive PT results in $22 \%$ of CSU patients (35 of 162) with common allergens, and in $6.9 \%$ of CSU patients (11 of 158) with a series of penicillins. Some patients with positive penicillin allergy improved with strict adherence to a milkabstinent diet. Warin and Smith ${ }^{12}$ used an immediate PT (IPT) and patient-performed PT, followed by a challenge test with edible capsules containing the allergen. However, the authors were unable to draw unequivocal conclusions regarding the relevance of the PT to chronic urticaria.

Later, this issue was explored by Guerra et al. ${ }^{13}$ Their study demonstrated that 50 of 121 patients (41\%) with CSU tested positive for contact allergens, making contact

Table 2 Ten Topmost Allergens Causing Reactions in the CD Group, and Their Respective Number of Reactions Causing in the CSU Group

\begin{tabular}{|c|c|c|c|c|}
\hline \multirow[t]{3}{*}{ Allergen } & \multirow{2}{*}{\multicolumn{2}{|c|}{$\frac{\text { CD Group }(n=680)}{\text { Reactions }}$}} & \multirow{2}{*}{\multicolumn{2}{|c|}{$\frac{\text { CSU Group }(n=134)}{\text { Reactions }}$}} \\
\hline & & & & \\
\hline & Total & Relevant & Total & Relevant \\
\hline Nickel & $102(15 \%)$ & $22(3.2 \%)$ & $27(20.1 \%)$ & $2(1.5 \%)$ \\
\hline Methylchloroisothiazolinone/Methylisothiazolinone (MCI/MI) & $38(5.6 \%)$ & $35(5.1 \%)$ & $5(3.7 \%)$ & $0(0 \%)$ \\
\hline Methylisothiazolinone & $30(4.4 \%)$ & $29(4.3 \%)$ & I (0.7\%) & $0(0 \%)$ \\
\hline Fragrance Mix I & $25(3.7 \%)$ & $14(2.1 \%)$ & $6(4.5 \%)$ & $0(0 \%)$ \\
\hline Myroxolon pereirae & $24(3.5 \%)$ & $\mathrm{II}(\mathrm{I} .6 \%)$ & $2(1.5 \%)$ & $0(0 \%)$ \\
\hline Potassium dichromate & $15(2.2 \%)$ & $8(1.2 \%)$ & $2(1.5 \%)$ & I $(0.7 \%)$ \\
\hline Thimerosal & $15(2.2 \%)$ & I (0.1\%) & $0(0 \%)$ & $0(0 \%)$ \\
\hline Epoxy resin & $12(1.8 \%)$ & $3(0.4 \%)$ & I (0.7\%) & $0(0 \%)$ \\
\hline Cobalt & 12 (I.8\%) & I (0.I\%) & $4(3 \%)$ & I (0.7\%) \\
\hline p-Phenylene diamine (PPD) & II (1.6\%) & $9(1.3 \%)$ & $3(2.2 \%)$ & $0(0 \%)$ \\
\hline
\end{tabular}

Abbreviations: CD, Contract Dermatitis; CSU, Chronic spontaneous urticaria. 
allergens the lead etiology of their condition. In all patients in their cohort, avoidance measures led to complete remission within 1 month. Similar results were found in a more recent study, ${ }^{14}$ where 233 of $543(42.9 \%)$ patients with CSU had a positive PT, and a statistically significant improvement in their condition through appropriate contact allergen avoidance.

In contrast, somewhat different results were shown in another study; ${ }^{15}$ in this report, 23 patients with CSU, in whom previous workup had failed to demonstrate an etiology, were patch tested. Of this cohort, 22 patients had a positive PT (95\%) but only 8 of the 22 patients (35\%) experienced improvement of their symptoms upon avoidance of the culprit allergen.

In another study, ${ }^{16}$ patients with severe CSU were tested using T.R.U.E Test ${ }^{\circledR}$, a ready-to-use PT. Spontaneous improvement was observed in all groups (those with a positive test that were instructed to avoid the contact allergens, those with a negative test, and the control group), casting doubt as to the relevance of PT results to the management of CSU.

The use of the PT technique with common aero- and food- allergens instead of the standard contact allergens, has also been reported. ${ }^{17}$ This process, known as the atopy PT, demonstrated that 17 of 120 children with CSU (14.1\%) were sensitized to food additives. The authors concluded that the atopy PT may be useful in CSU.

As these studies demonstrate contradicting results, the current guidelines ${ }^{2}$ recommend performing skin tests and/ or allergen avoidance tests — only as "Extended diagnostic program" and not as part of the routine diagnostic tests. The exact nature of the skin tests is not defined in the guidelines.

Our study indicate that contact allergy may underlie a small number of CSU cases. We found that in 3\% of cases, the detection of contact allergies was relevant to CSU management. Metals and textile dyes were found to be the culprit for CSU. Since Nickel intake is mentioned to be a causative factor for $\mathrm{CSU},{ }^{19}$ low Nickel or Cobalt revised, point-based $\operatorname{diet}^{20}$ was proposed to all CSU patients who reacted to these metals. Three of them showed complete remission of the symptoms after 3 months of strict avoidance. The patient who reacted to chloramphenicol reported that the onset of his symptoms was clearly associated with widespread prolonged application of chloramphenicol ointment. ${ }^{21}$
Considering the chronic and recalcitrant course of $\mathrm{CSU}$, the benefit of this simple diagnostic procedure should not be underestimated.

Our study had several limitations. The sample of patients with CSU was relatively small. All cases were evaluated retrospectively. There are some significant differences between the patients and control groups that may affect the results. Another bias is that only CSU patients with positive reactions were asked about possible role of haptens.

In conclusion, our results suggest that performing PT and avoiding contact allergens may assist in the management of some CSU patients. Further studies are required in order to characterize this subgroup.

\section{Disclosure}

The authors report no conflicts of interest for this work.

\section{References}

1. Antia C, Baquerizo K, Korman A, et al. Urticaria: a comprehensive review: epidemiology, diagnosis, and work-up. J Am Acad Dermatol. 2018;79(4):599-614. doi:10.1016/j.jaad.2018.01.020

2. Zuberbier T, Aberer W, Asero R, et al. The EAACI/GA ${ }^{2} \mathrm{LEN} / \mathrm{EDF} /$ WAO guideline for the definition, classification, diagnosis and management of urticaria. Allergy. 2018;73(7):1393-1414. doi:10.1111/ all.13397

3. Maurer M, Weller K, Bindslev-Jensen C, et al. Unmet clinical needs in chronic spontaneous urticaria. A GA ${ }^{2} \mathrm{LEN}$ task force report. Allergy. 2011;66(3):317-330. doi:10.1111/j.1398-9995.2010.02496.x

4. Maurer M, Abuzakouk M, Bérard F, et al. The burden of chronic spontaneous urticaria is substantial: real-world evidence from ASSURE-CSU. Allergy. 2017;72(12):2005-2016. doi:10.1111/ all.13209

5. Kaplan AP, Greaves M. Pathogenesis of chronic urticaria. Clin Exp Allergy. 2009;39(6):777-787. doi:10.1111/j.1365-2222.2009.03256.x

6. Vocanson M, Hennino A, Rozières A, et al. Effector and regulatory mechanisms in allergic contact dermatitis. Allergy. 2009;64 (12):1699-1714. doi:10.1111/j.1398-9995.2009.02082.x

7. Johansen JD, Aalto-Korte K, Agner T, et al. European Society of Contact Dermatitis guideline for diagnostic patch testing - recommendations on best practice. Contact Dermatitis. 2015;73 (4):195-221. doi:10.1111/cod.12432

8. Stingeni L, Bianchi L, Tramontana M, et al. Skin tests in the diagnosis of adverse drug reactions. G Ital Dermatol Venereol. 2020;155:602-621. doi:10.23736/S0392-0488.20.06698-5

9. Solensky R, Khan DA. Evaluation of antibiotic allergy: the role of skin tests and drug challenges. Curr Allergy Asthma Rep. 2014;14:459. doi:10.1007/s11882-014-0459-z

10. Ohtsu H, Seike M. Histamine and histamine receptors in allergic dermatitis. Handb Exp Pharmacol. 2017;241:333-345.

11. Boonk WJ, van Ketel WG. Skin testing in chronic urticaria. Dermatologica. 1981;163(2):151-159. doi:10.1159/000250152

12. Warin RP, Smith RJ. Chronic urticaria Investigations with patch and challenge tests. Contact Dermatitis. 1982;8(2):117-121. doi:10.1111/ j.1600-0536.1982.tb04156.x 
13. Guerra L, Rogkakou A, Massacane P, et al. Role of contact sensitization in chronic urticaria. J Am Acad Dermatol. 2007;56(1):88-90. doi:10.1016/j.jaad.2006.07.023

14. Chen H, Liu G, Huang N, et al. Incidence of allergic contact sensitization in central Chinese subjects with chronic urticaria. An Bras Dermatol. 2016;91(2):168-172. doi:10.1590/abd1806-4841.20164606

15. Hession MT, Scheinman PL. The role of contact allergens in chronic idiopathic urticaria. Dermatitis. 2012;23(3):110-116. doi:10.1097/ DER.0b013e318250b448

16. Magen E, Mishal J, Menachem S. Impact of contact sensitization in chronic spontaneous urticaria. Am J Med Sci. 2011;341(3):202-206. doi:10.1097/MAJ.0b013e3181ff2570

17. Ozceker D, Dilek F, Yucel E, et al. Can allergy patch tests with food additives help to diagnose the cause in childhood chronic spontaneous urticaria? Postepy Dermatol Alergol. 2020;37(3):384-389. doi:10.5114/ada.2020.96909
18. Tupker RA, de Monchy JG, Coenraads PJ. House-dust mite hypersensitivity, eczema, and other nonpulmonary manifestations of allergy. Allergy. 1998;53(48 Suppl):92-96. doi:10.1111/j.13989995.1998.tb05006.x

19. Abeck D, Treanckner I, Steinkraus V, et al. Chronic urticaria due to nickel intake. Acta Dermatol Venereol. 1993;73:438-439.

20. Stuckert J, Nedorost S. Low-cobalt diet for dyshidrotic eczema patients. Contact Dermatitis. 2008;59(6):361-365. doi:10.1111/ j.1600-0536.2008.01469.x

21. Schewach-Millet M, Shpiro D. Urticaria and angioedema due to topically applied chloramphenicol ointment. Arch Dermatol. 1985;121(5):587. doi:10.1001/archderm.1985.01660050035002

\section{Publish your work in this journal}

The Journal of Asthma and Allergy is an international, peer-reviewed open-access journal publishing original research, reports, editorials and commentaries on the following topics: Asthma; Pulmonary physiology; Asthma related clinical health; Clinical immunology and the immunological basis of disease; Pharmacological interventions and

Submit your manuscript here: https://www.dovepress.com/journal-of-asthma-and-allergy-journal new therapies. The manuscript management system is completely online and includes a very quick and fair peer-review system, which is all easy to use. Visit http://www.dovepress.com/testimonials.php to read real quotes from published authors. 